Original paper

\title{
Epidemiological investigation on hepatitis A virus infection outbreak in the area of Rzeszow city during the years 2017/18
}

\author{
Andrzej Cieśla', Monika Bociąga-Jasik², Jerzy Sieklucki', Robert Pleśniak ${ }^{1}$ \\ 'Institute of Medical Studies, Medical College of Rzeszów University, Poland \\ 2Department of Infectious Diseases, Jagiellonian University Medical College, Krakow, Poland
}

\begin{abstract}
Aim of the study: To define the threats and epidemiological differences between outbreaks of hepatitis A (HA) in adults and children, and to assess the efficiency of implemented prophylaxis. We also present a summary of treatment and sick leave costs as compared to the predicted money-load in the case of properly initiated prophylaxis in hepatitis A virus (HAV)-exposed persons.
\end{abstract}

Material and methods: The cause of two outbreaks was contamination related to food mishandling by a person infected with HAV. Especially health-threatening was exposure to the infection of 137 pre-school children. A second outbreak caused by the same source was observed among 25 exposed adults. On the basis of medical documentation we determined costs related to hospitalization and sickness leave absence at work, comparing it with money load related to implementation of required prophylaxis in both groups of people exposed to risk of HAV infection.

Results: As a consequence of exposure in the kindergarten area, an infection was confirmed in 32 patients from the first and subsequent generations and 7 cases were observed in the second outbreak. Costs of hospitalization and related to the sick leave were estimated to double the predicted costs of prophylaxis.

Conclusions: In the case of lack of proper hand hygiene of a food handler with HA or in the case of food-borne exposure of children to HAV it is necessary to apply post-exposure prophylaxis. Costs of the prophylaxis are significantly lower than costs of HA. Both outbreaks underwent self-limitation with longer course of morbidity and larger number in the case of the kindergarten focus.

Key words: hepatitis A, post-exposure prophylaxis, foodborne outbreak, costs of hepatitis A, vaccination against HAV for food handler.

Address for correspondence:

Andrzej Cieśla, Department of Infectious Diseases, University of Rzeszów, Poland, e-mail: andrzejciesla@mp.pl

\section{Introduction}

Incidence of acute hepatitis A (HA) in Podkarpacie (a south-eastern region of Poland) during 4 years preceding the described 2017 outbreak was estimated to reach numbers similar to the rest of Poland and ranged from 0.09 to 0.28 per 100,000 inhabitants. In 2017 , although this factor sharply rose to 2.87 , the rest of the country faced even more dramatic changes that doubled the one observed in Podkarpacie $[1,2]$. The majority of the cases observed in this region during the period of fall 2017 to spring 2018 were reported in Rzeszów city and proximal regions. A closer epidemiological investigation revealed the association of most of the observed hepatitis A virus (HAV) cases with clinically overt HA in a single person. The patient, diagnosed on $27^{\text {th }}$ September 2017 after 5 days of symptomatic disease, was a 34-year-old man, employed as a cook at the local kindergarten. Upon interview, no previous HAV vaccination was reported, and an out- 
break of the disease was coincidentally associated with a recent stay in Spain.

The group exposed to the infectious risk encompassed 137 children from the aforementioned kindergarten and 25 employees attending an open-air company event on $23^{\text {rd }}$ September 2017, where meals were prepared by patient 0 . As a consequence of exposure in the kindergarten area, an infection was confirmed in 32 patients from the $1^{\text {st }}$ and subsequent generations and 7 cases were observed in the case of participants of the open-air event. During the initial phases of the outbreak, despite availability of 100 vaccine doses at the local sanitary-epidemiological station, only 2 individuals exposed to the risk of infection decided to undergo this active prophylaxis, and did not display any symptoms of HA later.

Lack of pediatric vaccines prevented effective launching of a similar prophylactic paradigm in exposed children. As a consequence of not enforcing the desirable vaccination regimen, several cases of secondary infections were observed in the environment of $1^{\text {st }}$ generation patients. In total, the first wave of infections encompassed 6 employees participating in get-together party and 7 children, 3 persons from the kindergarten staff, and 2 parents who consumed meals prepared at the daycare center. The $2^{\text {nd }}$ generation was limited to a wife of a patient from the former source and 20 members of children's families from the latter. In total, up to 4 generations of cases were observed in the case of larger families. A pattern in occurrence of new infections, with characteristic periodicity in appearance of new generations of patients, is consistent with the incubation period of the disease $[3,4]$. Namely, the first wave of infected patients was observed at the end of October 2017, followed by November and

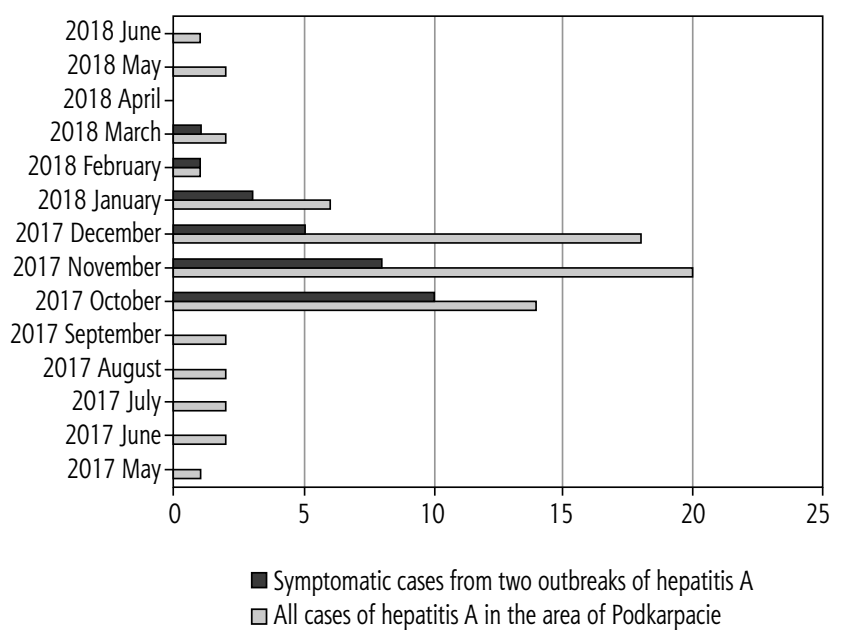

Fig. 1. Registry of cases of hepatitis $A$ in the area of Podkarpackie voivodeship from May 2017 until June 2018
December outbreaks, with the last cases that might be linked to the described patient 0 observed in March 2018 (Fig. 1).

A notable group not directly related to the previously described cases consisted of 5 young male patients acquainted with patient 0 , who identified themselves as heterosexual, and did not report any risky sexual behaviors whose clinically active disease was observable simultaneously with consecutive generations of patients described before. Given the information on the sexual preferences of patient 0 and his homosexual orientation, it is feasible to speculate on a sexual contacts-related way of spread of hepatitis in this patient subset. This hypothesis may be further corroborated by the testimony of a wife of one of these patients, diagnosed with secondary infection, which confirmed MSM (men who have sex with men) contacts of her husband.

After March 2018, and the last cases that may be linked back to the source of infection identified at the kindergarten, the incidence of HAV infections recovered to the previously observed levels, with all new cases not being directly associated with the outbreak described herein.

The aim of the present report was to define the threats and epidemiological differences between outbreaks in adults and children, and to assess the efficiency of implemented HA prophylaxis. We also present a summary of treatment and sick leave costs as compared to the predicted money-load in the case of properly implemented prophylaxis in HAV-exposed persons.

\section{Material and methods}

The causal-temporal relationship between HAV infection in patient 0 and the outbreak of two foci of HA was established on the basis of an epidemiological enquiry carried out by the Public Health Department in Rzeszów. Diagnosis of HA was determined on grounds of presence of biochemical signs (alanine aminotransferase [ALT], aspartate aminotransferase [AST], bilirubin and international normalized ratio [INR]) of an acute liver injury and confirmed by testing for HA specific immunoglobulin (Ig) M antibodies (VIDAS HAV IgM bioMérieux France) via ELISA. To rule out the possibility of co-infection with hepatitis $\mathrm{B}$ (HBV) and $\mathrm{C}$ virus ( $\mathrm{HCV})$, we determined levels of antibodies against $\mathrm{HCV}, \mathrm{HBc}$ IgM and presence of $\mathrm{HBs}$ antigen. With the exception of 7 children and 3 adults treated at General Practitioner Wards, all patients were hospitalized or ambulatorily consulted at the Department of Infectious Diseases in Łańcut. For both foci 
of infection, methods to counteract the spread of the infection were implemented. In particular, effort was made to 1) identify the source of contamination and 2) inform the patients from the groups of direct contact on post-exposure prophylaxis methods. During the outbreak of the first cases of HA screening tests were performed for presence of anti-HAV IgG class of immunoglobulins in exposed children, and adult patients were provided with the possibility of antiHAV prophylactic vaccination. The study presented herein aims to understand the efficiency of these actions as compared to actual guidelines described in the literature. Finally, on the basis of medical documentation we determined costs related to hospitalization and sickness leave absence at work, comparing it with money load related to implementation of required prophylaxis in both groups of people exposed to risk of HAV infection.

\section{Results}

Characteristics of patients from both outbreaks of HA are presented in Tables 1-3. Further from that, we present the statistics for Podkarpacie on the diagnosis of HA at the turn of the years 2017 and 2018. This data are complemented by the results on the number of symptomatic HAV infected patients from both foci of the described outbreak hospitalized and treated in the Department of Infectious Diseases in tańcut (Fig. 1). Cases of symptomatic HA in both foci of the outbreak established $45.9 \%$ of all registered HAV infections in Podkarpacie, and both symptomatic and non-symptomatic cases linked with the foci: $63.9 \%$. If we include in that number the 6 persons who had HA probably as a result of MSM contacts with patient 0 , this value should be increased to $73.7 \%$.
The cost of hospitalization was calculated based on the guidelines from procedure DRG (diagnosis-related group) G16 for patients with acute hepatitis admitted to the Department and hospitalized for more than 6 days. Based on that, the 14 cases of the outbreak at the kindergarten consumed as much as PLN 43,918, with an additional PLN 18,822 related to the disease in 6 patients from the integration meeting focus. Costs of temporary inability to work, which also included the hospitalization and 30-day leave of absence related to disease, were calculated based on the average monthly salary in the private sector in 2017 and were estimated to reach PLN 21,199. For 5 people from the group of kindergarten employees and parents, the analogous calculation was made, to give the sum of PLN 8,138. Therefore, total cost related to the described HAV outbreak can be estimated to be as high as PLN 92,011. Instead, the cost of two doses of vaccination for 137 children and 25 adults exposed to the risk of infection in both foci is PLN 47,860 (52.01\% of the actual costs related to the hospitalization). Despite the fact that a single dose of vaccination is sufficient to prevent the development of HA [5], in the foci of the outbreak where in most cases of exposure no contact with the virus happened, for the development of sustained immunity a second dose of vaccine is required. For the kindergarten epicenter, the additional costs should be calculated because of the unknown and difficult to estimate number of adults that were exposed to risk of infection due to the consumption of the meals prepared for their children.

\section{Discussion}

The cause of occurrence of both outbreaks of HA was food contamination by patient 0 , who was pre-

Table 1. Characteristics of the focus of HAV infections connected with kindergarten exposures

\begin{tabular}{lcc}
\hline Parameter & & \\
\hline Exposure & 137 children & \\
\hline Children with hepatitis A under 6 years old & 16 (9 boys, 7 girls $)$ & Median age 4.5, IQR 3 years \\
\hline Siblings of children from kindergarten with hepatitis A & 4 (3 boys, 1 girl $)$ & Median age 12, IQR 4.5 years \\
\hline Adults with hepatitis A & 12 & Median age 31.9, IQR 6 years \\
\hline Parents & $9(6$ females, 3 males $)$ & \\
\hline Kindergarten workers & 3 (3 females $)$ & National Insurance costs PLN 43,918 \\
\hline Hospitalizations & 14 & Costs PLN 7,875 \\
\hline Sick leaves & 5 persons (median 30 days) & Total costs PLN 51,793
\end{tabular}


Table 2. Characteristics of the focus of HAV infections connected with exposures during integrative meeting

\begin{tabular}{lc}
\hline Parameter & \\
\hline Exposure & 25 persons \\
\hline Number of patients with hepatitis A & 7 (2 females, 5 males) \\
\hline Median age & 34.5, IQR 10.5 years \\
\hline National Insurance costs (6 hospitalizations) & 18,882 PLN \\
\hline $\begin{array}{l}\text { Costs of temporal inabilities to work lasting } \\
\text { at average } 29 \text { days }\end{array}$ & 27,354 PLN \\
\hline
\end{tabular}

$I Q R$ - interquartile range

paring meals at the time of high infectivity preceding symptoms of disease [3]. According to parents who were the first generation of patients, the source of infection was fruits (apples and pears) received by children in kindergarten. In the case of the integrative meeting the amount of food products which may be the source of infection were larger and included snacks and grilled dishes served by the ill person.

$\mathrm{HAV}$ is characterized by high resistance to environmental factors. On hand surfaces it remains infectious for at least 4 hours, enabling easy and long lasting contamination of kitchen equipment [6, 7]. An extension of time of HAV infectivity is observed if contaminated food products are kept in a fridge or freezer $[8,9]$.

In comparison to the first generation of infections which was food-borne, secondary cases in both outbreaks were caused by viral spread in household conditions [10].

A characteristic feature of the kindergarten outbreak was a greater risk of propagation of secondary infections as a consequence of children illnesses in relation to the outbreak containing only adults in the proportion $4: 3$ vs. $6: 1$. Higher risk of transmission of HAV was related to problems with maintaining hygienic principles in a children environment as well as the frequent asymptomatic course of illness in this group of patients [11].
Verification of the hypothesis of propagation of infection by MSM contacts of patient 0 was impossible due to the lack of HAV genome fragment sequencing, which is standard for epidemiological inquiries in such cases [12-14]. Allowing this hypothetic additional way of HAV transmission, the total number of infections secondary to patient 0 is increased to 45 (Table 3 ).

A risk of HAV transmission connected with food preparation in catering facilities is not clearly defined in publications and vaccination of clients consuming dishes prepared by persons with HA is not unambiguously recommended [15]. However, most of the reports indicate a threat of transfer of HAV infection from a food handler to non-immunized persons [14]. A current challenge is the globalization of production and trade of food connected with the risk of an occurrence of large outbreaks of HA caused by consumption of HAV contaminated fruits and vegetables [12, 16-18]. Such changes in HAV epidemiology proceed in line with the increasing number of non-immunized persons with a switch of HAV infections to older groups of patients and with an increased risk of HA complications $[19,20]$.

To prevent the risk of transmission of HAV infection, some regulations describe the necessity of immunization against HAV among workers employed as food handlers. Due to rare cases of occurrence of food-borne HAV infections as well as costs of immunization, vaccinations of such groups of employees are regarded as not cost-effective in preventing HAV infections [21].

The last outbreak of HAV infection in Europe and North America among MSM and HIV infected individuals should increase awareness among health care professional that infections can be spread by sexual contacts as well [22]. The vaccination against HAV should be routinely offered among MSM, bisexual, transgender as well as heterosexual with risky sexual behaviors $[12,23,24]$.

Table 3. Number of registered cases of hepatitis A linked with HAV infection of the worker of a catering facility

\begin{tabular}{lccc}
\hline Patient $\mathbf{0}$ & & & \\
\hline Focus & Integrative meeting & Kindergarten & MSM? \\
\hline First generation of patients & 6 & 16 & 2 \\
\hline Second generation & 1 & 12 & 2 \\
\hline Third generation & & 2 & 2 \\
\hline Fourth generation & 7 & 32 & 6 \\
\hline Number of HAV infected persons in separate focuses & & $45(39+6 ?)$
\end{tabular}

Patient 0 - worker of a catering facility infected with HAV; Integrative meeting - focus of HAV infections connected with an integrative meeting of employees; Kindergarten - focus of HAV infections among children, their families and kindergarten workers; MSM? - HAV infections among men who have sex with men as well as the wife of one of the MSM men 
Also attention is drawn to the necessity of keeping high hygienic standards with special consideration of hand washing and limitations in work performance in cases of developing ambiguous symptoms of an illness $[3,25]$. The integrative open-air meeting precluded compliance with proper hygiene rules for a highly infectious person and should be an indication for incorporation of post-exposure prophylaxis for all non-immunized participants. The necessity of application of post-exposure HA prophylaxis in the case of the kindergarten focus resulted from the high epidemiological risk as a consequence of spread of HAV infections in a group of children aged under 6 years [26].

Due to the above-mentioned reasons a decision of implementation of HAV infection prophylaxis in both groups of exposed persons should take place at the moment of diagnosis of $\mathrm{HA}$ in patient 0 . All persons who revealed HA in the analyzed outbreaks due to age and lack of medical contraindications should be qualified for post-exposure prophylaxis using vaccination only $[3,23]$. Active application of post-exposure prophylaxis in the case of a HA outbreak effectively limits further transmission of infection.

Low utilization of vaccines in limitation of infection spreading in analyzed focuses suggests the necessity of institution of highly specialized medical advice, qualification and surveillance of applied prophylaxis with accessibility of vaccines against HA for all age groups.

An analysis of costs of sick absences of adult persons from both focuses, hospital and ambulatory treatment of all patients with HA, revealed that they were twice as high as the costs of two-dose vaccination of a large group of 137 children from the kindergarten and 25 adults from the integrative meeting. An unexpected group of persons exposed to HA who needed to be taken into consideration in prophylaxis were kindergarten workers as well as parents consuming meals designated for children.

Apart from the above-described exception, both groups of persons exposed to HAV transmission from patient 0 were easy to identify, which is not a frequent situation in case of epidemiological inquiries during food-borne HAV infections [27]. In most such cases clients of catering facilities remain anonymous and require special methods of identification [28].

Due to the frequent asymptomatic course of HA among children under 6 years old, the actual number of HAV infections was probably higher than registered [4]. An assessment of real number of HAV infections would be possible using another identification of antiHAV IgG antibodies in this group.

Uncontrolled HAV spread induced by the asymptomatic course of HA might be a cause of diseases epi- demiologically not connected with the primary focus. The lack of HAV genome fragment sequencing from ill patients makes it impossible to describe any connection with sporadically noted HA cases during the course and after disappearance of illnesses in investigated focuses [12-14].

Self-limitation of HA with low utilization of methods of post-exposure prophylaxis indicate the essential significance of current hygienic standards, and access to clean water and water closets in preventing further transmission of infections.

\section{Conclusions}

Vaccination against HAV should be routinely offered for food handlers.

People from the high-risk group of HAV infection, including MSM, should be vaccinated against HAV. Medical staff should be informed about the higher risk of HA among MSM and necessity of determination of MSM status during work-up with patients infected with HAV.

In the case of lack of proper hand hygiene of a food handler with $\mathrm{HA}$ or in the case of foodborne exposure to HAV in children it is necessary to apply post-exposure prophylaxis.

Costs of post-exposure prophylaxis given to even a large group of persons are significantly lower than costs of treatment and work inability connected with disease.

In spite of insufficient actions aiming to limit the spread of infection in the form of lack of vaccinations, both outbreaks underwent self-limitation with a longer course of morbidity and larger number of secondary infections in the case of the kindergarten focus.

\section{Disclosure}

The authors declare no conflict of interest.

\section{References}

1. Zachorowania na wybrane choroby zakaźne w Polsce od 1 stycznia do 31 grudnia $2017 \mathrm{r}$. oraz w porównywalnym okresie $2016 \mathrm{r}$. Zakład Epidemiologii NIZP-PZH. wwwold.pzh.gov.pl/oldpage/ epimeld/2017/INF_17_12B.pdf

2. Polański P, Kucharczyk B, Kondej B, et al. Hepatitis A in Poland in 2017 - epidemic increase cases. Przegl Epidemiol 2019; 73: 487-497.

3. Averhoff F, Khudyakov Y, Bell BP. Hepattis A virus in Mandell, Douglas and Bennett's principles and practice of infectious diseases. Saunders, Elsevier Inc. 2015.

4. Lemon SM, Ott JJ, Van Damme P, et al. Type A viral hepatitis: A summary and update on the molecular virology, epidemiology, pathogenesis and prevention. J Hepatol 2017. pii: S01688278(17)32278-X. doi: 10.1016/j.jhep.2017.08.034. 
5. Parrón I, Planas C, Godoy P, et al. Effectiveness of hepatitis A vaccination as post-exposure prophylaxis. Hum Vaccin Immunother 2017; 13: 423-427.

6. Mbithi JN, Springthorpe VS, Boulet JR, et al. Effect of relative humidity and air temperature on survival of hepatitis A virus on environmental surfaces. Appl Environ Microbiol 1991; 57: 1394-1399.

7. Mbithi JN, Springthorpe VS, Boulet JR, et al. Survival of hepatitis A virus on human hands and its transfer on contact with animate and inanimate surfaces. J Clin Microbiol 1992; 30: 757-763.

8. Shieh YC, Stewart DS, Laird DT. Survival of hepatitis A virus in spinach during low temperature storage. J Food Prot 2009; 72: 2390-2393.

9. Butot S, Putallaz T, Sánchez G. Effects of sanitation, freezing and frozen storage on enteric viruses in berries and herbs. Int J Food Microbiol 2008; 126: 30-35.

10. Lima LR, De Almeida AJ, Tourinho Rdos S, et al. Evidence of hepatitis A virus person-to-person transmission in household outbreaks. PLoS One 2014; 9: e102925.

11. Armstrong GL, Bell BP. Hepatitis A virus infections in the United States: model-based estimates and implications for childhood immunization. Pediatrics 2002; 109: 839-845.

12. Severi E, Verhoef L, Thornton L, et al. Large and prolonged food-borne multistate hepatitis A outbreak in Europe associated with consumption of frozen berries, 2013 to 2014. Euro Surveill 2015; 20: 21192.

13. Nainan OV, Xia G, Vaughan G, et al. Diagnosis of hepatitis a virus infection: a molecular approach. Clin Microbiol Rev 2006; 19: 63-79.

14. Robertson BH. Viral hepatitis and primates: historical and molecular analysis of human and nonhuman primate hepatitis $\mathrm{A}, \mathrm{B}$, and the GB-related viruses. J Viral Hepat 2001; 8: 233-242.

15. Hall V, Abrahams A, Turbitt D, et al. No evidence of transmission from an acute case of hepatitis $A$ in a foodhandler: follow-up of almost 1,000 potentially exposed individuals, London, United Kingdom, April 2012. Euro Surveill 2014; 19: 20865.

16. Tricco AC, Pham B, Duval B, et al. A review of interventions triggered by hepatitis A infected food-handlers in Canada. BMC Health Serv Res 2006; 6: 157.

17. Petrignani M, Harms M, Verhoef L, et al. Update: a food-borne outbreak of hepatitis A in the Netherlands related to semi-dried tomatoes in oil, January-February 2010. Euro Surveill 2010; 15: 19572.

18. Wheeler C, Vogt TM, Armstrong GL, et al. An outbreak of hepatitis A associated with green onions. N Engl J Med 2005; 353: 890-897.

19. Carrillo-Santisteve P, Tavoschi L, Severi E, et al. ECDC HAV Expert Panel. Seroprevalence and susceptibility to hepatitis A in the European Union and European Economic Area: a systematic review. Lancet Infect Dis 2017; 17: e306-e319.

20. Ly KN, Klevens RM. Trends in disease and complications of hepatitis A virus infection in the United States, 1999-2011: a new concern for adults. J Infect Dis 2015; 212: 176-182.

21. Morey RJ, Collier MG, Nelson NP. The financial burden of public health responses to hepatitis a cases among food handlers, 2012-2014. Public Health Rep 2017; 132: 443-447.

22. Raczyńska A, Wickramasuriya NN, Kalinowska-Nowak A, et al. Acute hepatitis A outbreak among men who have sex with men in Krakow, Poland; February 2017-February 2018. Am J Mens Health 2019; 13: 1557988319895141.

23. Kozłowska-Jalowska A, Załęski A, Kuchar E, et al. Profilaktyka poekspozycyjna chorób zakaźnych. Cz. 2: wirusowe zapalenie wątroby typu A. www.mp.pl/szczepienia/artykuly/przegladowe/182888,profilaktyka- poekspozycyjna-wirusowego-zapalenia-watroby-typu-a
24. Nelson NP, Link-Gelles R, Hofmeister MG, et al. Update: Recommendations of the Advisory Committee on Immunization Practices for use of hepatitis A vaccine for postexposure prophylaxis and for preexposure prophylaxis for international travel. MMWR Morb Mortal Wkly Rep 2018; 67: 1216-1220.

25. Centers for Disease Control and Prevention (CDC). Foodborne transmission of hepatitis A, Massachusetts, 2001. MMWR Morb Mortal Wkly Rep 2003; 52: 565-567.

26. Advisory Committee on Immunization Practices (ACIP), Fiore AE, Wasley A, Bell BP. Prevention of hepatitis A through active or passive immunization: recommendations of the Advisory Committee on Immunization Practices (ACIP). MMWR Recomm Rep 2006; 55 (RR-7): 1-23.

27. Dwyer DM, Strickler H, Goodman RA, et al. Use of case-control studies in outbreak investigations. Epidemiol Rev 1994; 16: 109-123.

28. Tekeuchi Y, Kobayashi G, Matui Y, et al. Outbreak of food-borne infection with hepatitis A virus. Jpn J Infect Dis 2006; 59: 346. 